\title{
Effect of obesity and exercise on the expression of the novel myokines, Myonectin and Fibronectin type III domain containing 5
}

Metabolic dysfunction in skeletal muscle is a major contributor to the development of type 2 diabetes. Endurance exercise training has long been established as an effective means to directly restore skeletal muscle glucose and lipid uptake and metabolism. However, in addition to the direct effects of skeletal muscle on glucose and lipids, there is renewed interest in the ability of skeletal muscle to coordinate metabolic activity of other tissues, such as adipose tissue and liver. The purpose of this study was to examine the effects of endurance exercise on the expression level of two novel muscle-derived secreted factors, or myokines, Myonectin and Fibronectin type III domain containing 5 (Fndc5), the precursor for Irisin. Methods: We used the diaphragm muscle from both the obese Zucker rat (OZR) and lean Zucker Rat (LZR) with 9 weeks of aerobic training on a motorized treadmill. We examined the gene expression of 12 commonly used reference genes and performed quantitative real-time PCR analysis on the gene expression of Myonectin and Fndc5.

Results: Of the 12 commonly used PCR reference genes tested we were able to establish that Hypoxanthine phosphoribosyltransferase 1 (HPRT1) and lactate dehydrogenase A (Ldha) remained stable in the diaphragm muscle regardless of obesity or exercise training. Interestingly, we also concluded that the commonly used reference genes: beta-Actin, beta-2microglobulin, Non-POU domain containing, octamer-binding, Peptidylprolyl isomerase $\mathrm{H}$, $18 \mathrm{~S}$ ribosomal rna, TATA box binding protein and Transferrin receptor were all found to be altered by the combination of exercise and obesity. Our study showed that the diaphragm muscle of the OZR had significantly higher expression levels of both myonectin and Fndc5. Exercise training had no effect on the expression level of Fndc5, but significantly lowered the 
gene expression of myonectin in both the LZR and OZR groups. Conclusion: Contrary to prior findings regarding the regulation of Fndc5 and myonectin we show that myonectin and Fndc5 expression are both increased in the OZR model of obesity. Further, long-term exercise training decreases myonectin levels, which is opposite, the effect reported with short-term exercise. However, this report confirms earlier work showing that Fndc5 gene expression is not altered by chronic exercise. 
12

13

14

15

16

17

18

19

20

21

22

23

24

25

26

27

28

29

30

31

32

33

34

35

36

37

38

39

40

41

42

43

44

Effect of obesity and exercise on the expression of the novel myokines, Myonectin and Fibronectin type III domain containing 5

Jonathan M. Peterson ${ }^{1,2}$, Ryan Mart ${ }^{2}$, and Cherie E. Bond ${ }^{3}$ From the ${ }^{1}$ Department of Health Sciences, College of Public Health, ${ }^{2}$ Quillen College of Medicine, East Tennessee State University, Johnson City TN 37614 and ${ }^{3}$ Ferrum College, Ferrum, VA. 24088

Running head: Long-term exercise training reduces myonectin levels ${ }^{4}$ Address correspondence to: Jonathan M. Peterson, Ph.D., Department of Health Sciences, College of Public Health, East Tennessee State University, Johnson City TN

Metabolic dysfunction in skeletal muscle is a major contributor to the development of type 2 diabetes. Endurance exercise training has long been established as an effective means to directly restore skeletal muscle glucose and lipid uptake and metabolism. However, in addition to the direct effects of skeletal muscle on glucose and lipids, there is renewed interest in the ability of skeletal muscle to coordinate metabolic activity of other tissues, such as adipose tissue and liver. The purpose of this study was to examine the effects of endurance exercise on the expression level of two novel muscle-derived secreted factors, or myokines, Myonectin and Fibronectin type III domain containing 5 (FNDC5), the precursor for Irisin.

Methods: We performed immunoblot analysis and quantitative real-time PCR analysis of Myonectin and FNDC5 in the diaphragm muscles of obese Zucker rat (OZR) and lean Zucker rat (LZR) with 9 weeks of aerobic training on a motorized treadmill. Results: We show that myonectin gene expression is increased in the OZR model of obesity and decreases with exercise in both lean and obese Zucker rats. Conversely, myonectin protein concentration was elevated with exercise. Similarly, FNDC5 mRNA levels are significantly higher in the OZR, however exercise training had no effect on the expression level of FNDC5 in either the LZR or OZR. We did not observe any difference in muscle protein content of Irisin with obesity or exercise. Conclusion: Our data shows that exercise training does not increase either FNDC5 or myonectin gene expression, indicating that increased transcriptional regulation of these myokines is not induced by exercise. However, our data also indicates a yet to be explored disconnect between myonectin gene expression and protein content. Further, this report highlights the importance of verifying reference genes when completing gene expression analysis. We found that many commonly used reference genes varied significantly by obesity and/or exercise and would have skewed the results of this study if used to normalize gene expression data. The unstable reference genes include: beta-Actin, beta-2-microglobulin, Non-POU domain containing, octamer-binding, Peptidylprolyl isomerase $\mathrm{H}, 18 \mathrm{~S}$ ribosomal RNA, TATA box binding protein and Transferrin receptor.

Key Words: Aerobic Training, Fatty Acids, Myonectin, Irisin, Metabolic Syndrome 
Obesity and diabetes are the top health problems in the developed

46 world, and major contributors to the development of cardiovascular disease

47 (1). Skeletal muscle metabolism is an important regulator in control of whole

48 body glucose and lipid homeostasis. Further, the reduction in insulin49 mediated skeletal muscle glucose uptake has long been recognized to be an 50 important underlying mechanism of type 2 diabetes (2). Lifestyle 51 modification, specifically increased physical activity, has demonstrated 52 enormous therapeutic potential to reverse skeletal muscle insulin resistance.

53

54

55

56

57

58

59

60

61

62

63

64

65

66

67

68

69

70

71

72

73

74

75

76

77

78

79

80

81

82

83

84

85

86

87

While the direct role of skeletal muscle metabolism in regulating glucose and lipid metabolism is well established, the potential endocrine-like functions of skeletal muscle to influence glucose and lipid metabolism in other tissues have only recently begun to be investigated. With the advent of proteomics, a number of muscle-derived secreted factors, collectively called myokines, have been identified $(3,4)$. Interleukin $6($ IL-6) is the first and most well studied myokine, and it is increased with exercise (5-7). IL-6 acts to stimulate hepatic glucose production and enhances glucose uptake by insulin-sensitive tissues $(8,9)$. These studies have provided the first endocrine-like function of skeletal muscle and established a link between exercise and systemic metabolic parameters (10). In addition to IL-6, a large number of other muscle-derived secretory proteins have been identified. The purpose of this paper was to examine the impact of obesity and chronic exercise training on two of these novel myokines: 1) fibronectin type III domain containing 5 (FNDC5), and 2) Clq TNF related Protein 15/myonectin, hereafter referred to as myonectin. FNDC5 is a membrane protein that is cleaved and it's proteolytic cleavage product is secreted as the hormone, irisin (11). Myonectin is a newly discovered protein with a characteristic Clq domain sequence shared by proteins within the novel CTRP protein family (12) .

Both myonectin and irisin have shown promise as therapeutic targets for metabolic diseases known to improve with exercise. Myonectin lowers circulating levels of free fatty acids by increasing uptake in adipose and liver tissues, and is increased with exercise, but lowered in a high fat diet model of obesity (12). Irisin, on the other hand, increases energy expenditure by inducing brown-fat-like conversion of white adipose tissue (11). However, the regulation of circulating irisin levels and FNDC5 gene expression by obesity and exercise are unclear and recently reviewed by Polyzos at el. (13). Briefly, exercise causes an increase circulating irisin protein levels and/or FNDC5 mRNA expression in some $(11,14,15)$, but not all studies $(14,16-20)$, whereas, obesity has either a positive $(13,14,17)$ or a negative $(20,21)$ association with irisin/FNDC5.

88

It is the purpose of this study to examine the combined effects of exercise and obesity on the regulation of myonectin and FNDC5 gene expression. This study may give clues to understanding the mechanism behind the endocrine benefits of regular exercise with obesity. 
90 Animals. The diaphragm muscles were kindly provided by the lab of Stephen 91 E. Alway, as reported from a previous study $(21,22)$. Briefly, equal numbers 92 of 6-wk-old male Obese Zucker rats (OZR) and lean zucker rats (LZR) (Harlan, 93 Indianapolis, IN) were randomly assigned to control (Control, $\mathrm{n}=8$ ) or 94 training (Exercised, $\mathrm{n}=8$ ) groups. The OZR is a genetic model of obesity due 95 to the presence of the recessive missense mutation ( $\mathrm{fa} / \mathrm{fa}$ ) in the leptin 96 receptor gene, whereas the LZR has a functioning leptin receptor ( $\mathrm{Fa} / \mathrm{fa}$ or $97 \mathrm{Fa} / \mathrm{Fa}$ ) (23-26). Compared to the LZR, the OZR exhibits severe obesity, 98 hyperphagia, hyperinsulinemia, hyperleptinemia, and hyperlipidemia (23-26). 99 Animals were housed in pathogen-free conditions, two per cage, at 20-22 C 100 with a reversed 12:12-h light-dark cycle, and fed rat chow and water ad 101 libitum throughout the study period. All animal procedures were conducted in 102 accordance with institutional guidelines, and ethical approval was obtained 103 from the Animal Care and Use Committee at West Virginia University (ACUC 104 \#07-0302).

105 Training Protocol. LZR and OZR were exercise trained by running on a level 106 motorized rodent treadmill (Columbus Instruments, Columbus, and $\mathrm{OH}$ ) 5 $107 \mathrm{~d} / \mathrm{wk}$ for $9 \mathrm{wk}$, as previously reported $(21,22)$. Briefly, during the first 4 wk, 108 the speed of the treadmill and duration of the training sessions was increased 109

112

113

114

115

116

117

118

119

120

121

122

123

124

125

126

127

128

129

130

131

132

133 gradually from a speed of $10 \mathrm{~m} / \mathrm{min}$ for 10 min to a final running speed of 20 $\mathrm{m} / \mathrm{min}$ for the OZR and $24 \mathrm{~m} / \mathrm{min}$ for the LZR. During the training sessions, mild electrical shock was applied, if necessary, to maintain the animals' running motivation. A slower final running speed was used in the OZR group to compensate for the increased intensity of exercise for these animals that resulted from their greater body weight as compared with LZR. As reported previously, the workload was estimated based on the following formula: Work $=1 / 2$ mass $*$ velocity squared $\left(\mathrm{W}=1 / 2 \mathrm{~m} * \mathrm{~V}^{2}\right)$. The average body weight of $500 \mathrm{~g}$ for the OZR and $350 \mathrm{~g}$ for the LZR were used to calculate the treadmill speeds to produce an approximate work output of $0.028 \mathrm{~J}$. These speeds were also reliably maintained by the OZR and LZR, with minimal requirements for external motivation by the investigators. This approach was successful as determined by similar increases in mitochondrial protein content and activity in the trained groups $(21,22)$. Animals assigned to the control group were handled daily and exposed to the noise of the running treadmill by placing their cages next to the treadmill during the exercise session.

Tissue collection. Forty-eight hours after the last training session and an overnight fast $(\sim 16 \mathrm{~h})$, the animals were anesthetized with injections of pentobarbital sodium (50 mg/kg ip) and euthanized via cardiac puncture. The diaphragm muscles were quickly removed, frozen immediately in liquid nitrogen and stored at $-80 \mathrm{C}$ until further analysis. It has been previously documented that exercise training has similar effects on the diaphragm as leg muscles (27). Further, we confirmed the expected increase in the mitochondrial protein Cytochrome c Oxidase Subunit IV (COX IV) as a marker of total mitochondrial content. 
134 RNA isolation and reverse transcription. Total RNA was extracted according to

135 standard procedures. Briefly, tissues were homogenized in Trizol reagent (Life

136 Technologies) using a Kinematica polytron in three $30 \mathrm{~s}$ bursts, separated by

$13710 \mathrm{~min}$ incubations on ice. After centrifugation at $13.2 \mathrm{rcf}, 4{ }^{\circ} \mathrm{C}$ for $5 \mathrm{~min}$ to

138 remove residual particulates, phase separation was accomplished using 3-

139 bromo-5-chloropentane, followed by centrifugation for $15 \mathrm{~min}$ at $13.2 \mathrm{rcf}, 4$

$140{ }^{\circ} \mathrm{C}$. RNA was precipitated from the aqueous phase by mixing with an equal

141 volume $70 \%$ ethanol, and then was loaded onto a nucleotide binding column

142 (RNeasy Mini-Kit, Qiagen). On-column DNA digestion was performed using

143 RNase-free DNase (Qiagen) to eliminate residual genomic DNA contamination

144 as per the manufacturer's instructions. RNA was eluted in $50 \mu \mathrm{l}$ RNase-free 145 water; purity (RIN $\geq 7.0$ ) and concentration were confirmed by microfluidic 146 capillary electrophoresis using an Agilent BioAnalyzer. $1 \mu \mathrm{g}$ total RNA of each 147 sample was reverse transcribed in a final volume of $20 \mu \mathrm{l}$, using GoScript ${ }^{\circledR}$ 148 cDNA synthesis reagents (Promega).

149 Analysis of reference genes. To screen for potential stable reference genes, 150 an aliquot 1 I of prepared cDNA from each animal was pooled by group and 151 treatment and the relative content of each reference gene was determined 152 by PCR array according to manufactures directions ( $\mathrm{RT}^{2}$ Profiler PCR Array; 153 Rat Housekeeping Genes; Qiagen PARN-000ZA). Assuming a perfect efficient 154 reaction, the difference between 1 quantification cycle $(\mathrm{Cq})$ equals a 2 -fold 155 difference in starting RNA quantity. Variability of reference genes was 156 deemed to be unacceptable if the maximum difference among the four 157 groups was greater than $0.5 \mathrm{Cq}$. Reference genes examined are listed in table 1582.

159 Quantitative real time PCR analysis. Validated PCR primers for Myonectin, 160 FNDC5/irisin, Hprt1, Ldha, and RN18S were purchased from SABiosciences 161 (Table 3). A 10-fold dilution series of DNA amplicons generated from an 162 untrained LZR rat muscle was employed as a standard curve for each gene of 163 interest, and the qPCR efficiency was determined for each gene, using a Bio164 Rad Cfx thermocycler. Briefly, $0.5 \mu$ of cDNA from the reverse transcription 165 reaction was incubated in appropriate mix (SABbiosciences) for an initial 166 denaturation at $94{ }^{\circ} \mathrm{C}$ for $30 \mathrm{~s}$, followed by 40 PCR cycles each consisting of $16795{ }^{\circ} \mathrm{C}$ for $0 \mathrm{~s}, 61{ }^{\circ} \mathrm{C}$ for $7 \mathrm{~s}$, and $72{ }^{\circ} \mathrm{C}$ for $10 \mathrm{~s}$. All qRT-PCR primers displayed 168 a coefficient of correlation greater than 0.99 and efficiencies between $90 \%$ 169 and $110 \%$. Data is reported as copy number per amount of starting RNA 170 (0.25 ng per reaction). Specificity of amplification products was further 171 confirmed by analyzing melting curve profiles for primers and products and 172 subjecting the amplification products to agarose gel electrophoresis.

173 Immunoblot Analysis. Diaphragm muscles were prepared in lysis buffer (20 $174 \mathrm{mM}$ Tris $\mathrm{pH} 7.5,150 \mathrm{mM} \mathrm{NaCl}, 1 \%$ Nonidet P-40, $0.5 \%$ sodium deoxycholate, $1751 \mathrm{mM}$ EDTA, $0.1 \%$ SDS) with protease and phosphatase inhibitor cocktails 176 (Sigma). The protein concentration was determined using a Coomassie Plus 177 protein assay reagent (Thermo Scientific). For each sample, $10 \mu \mathrm{g}$ of protein 
178 were loaded and separated on a SDS-polyacrylamide gel, according 179 manufactures direction (BioRad). The proteins were then transferred to 180 Nitrocelluloseous membranes blocked with milk and incubated with Rabbit 181 polyclonal anti-peptide antibody that can recognize myonectin (epitope 77182 KQSDKGI NSKRRSKARR-93). Myonectin antibody was kindly provided by the 183 lab of G.W. Wong and had been used previously (12). Glyceraldehyde 3184 phosphate dehydrogenase (GAPDH) antibody was purchased from Novus 185 Biologicals (NB300-221), COX IV antibody was purchased from Cell Signaling 186 Technology (4844), and FNDC5 antibody was purchased from Abcam 187 (ab131390). Antibody detection was performed with the appropriate 188 horseradish perioxidase-conjugated secondary antibodies. Visualizations 189 were completed with Multilmage III FuorChem ${ }^{\circledR}$ M (Alpha Innotech) and 190 quantifications were performed by Alphaview Software (Alpha Innotech).

191 Statistical analysis. Analyses were performed using GraphPad Prism ${ }^{\circledR} 5$ 192 software package. Student's T-test was used for comparisons between control 193 and exercise trained animals within the same genotype (figure 3). A one-way 194 ANOVA, followed by Bonferroni multiple comparisons post hoc analysis, were 195 performed when comparisons were made among all groups (figure 2). 196 Statistical significance was accepted at $P<0.05$. All data are given as means $197 \pm$ SE. No statistical analysis was performed on the PCR array data of pooled 198 samples (figure 1). A reference gene was deemed acceptable for further 199 analysis if the maximum Cq difference among the pooled samples from the 4 200 groups was less than 0.5 .

\section{Results and discussion}

202 The purpose of this study was to examine the regulation of myonectin and 203 FNDC5 in skeletal muscles of a genetic model of obesity and then to 204 determine the combined effects of obesity and exercise on the gene 205 expression of these two proteins. To our knowledge, this is the first study to 206 examine the effect of obesity combined with exercise training on skeletal 207 muscle gene expression of the novel myokines myonectin and FNDC5. 208 Although a number of cross sectional studies have compared irisin/FNDC5 209 levels to body mass index (BMI) the results have been contradictory $(14,17$ 210 19, 28-31). Based on the previous literature, we initially hypothesized that 211 the gene expression of both of these proteins would be reduced with obesity 212 and that the levels would increase with endurance exercise $(11,12)$.

213

214

215

216

217

218

219

220

Characterization of animals. Our goal in the training regime was to attempt to match final workload between the LZR and OZR. This approach was successful as determined by similar increases in mitochondrial protein content and activity in the trained groups $(21,22)$ and figure $1 \mathrm{~B}$. Although this workload was sufficient to lower body weight and fasting insulin levels (Table 1 ) in the OZR, it was not sufficient to induced significant changes in the LZR in these variables.

221 Identification of appropriate reference genes. Our data was able to confirm 
222 that HPRT, HSP90, Ldha, Pgk1, Rplp1, and Sdha remained relatively stable 223 (Cq variability less than 0.5 ) regardless of obesity or exercise training (Figure 224 1A). However, we also observed that there was greater than $1 \mathrm{Cq}$ difference, 225 among the groups examined, in gene expression of Actb, B2m, and Tfrc 226 (Figure $1 \mathrm{~A}$ and Table 2). Assuming an efficient reaction, $1 \mathrm{Cq}$ difference 227 represents an approximate 2 -fold difference in starting RNA content. This 228 indicates that some commonly used reference genes are effected by the 229 specific set of conditions described in this study and therefore are 230 inappropriate to use as reference genes, normalizing factors that control for 231 equal input of total RNA when performing relative gene expression analyses. 232 Further, these data highlight the importance of exploring the stability of 233 reference genes when performing GPCR analysis. It is possible that some of 234 the conflicting data regarding the regulation of FNDC5 mRNA could be due to 235 artifacts created by unreliable reference genes. Only one of the studies cited 236 in this manuscript confirmed reference gene expression was unchanged 237 between groups (19). Further, the two most commonly used reference genes 238 were 18S ribosomal RNA (RN18S) and Actb, both of which exhibited excessive 239 variability under experimental conditions, prohibiting their use as reference 240 genes in this model.

241 Of the stable reference genes, we performed quantitative qPCR analysis of 242 HPRT and Ldha to use as reference genes in our analysis. Quantitative qPCR 243 showed that there was no significant difference between the starting copy 244 number of HPRT and Ldha among the groups in our analysis (Figure 2D and 245 Figure 2E). Interestingly, the reference gene RN18S was also examined by 246 quantitative PCR analysis and found to be significantly elevated in the obese 247 exercised group compared to all other groups.

248 Effect of Obesity on Myonectin and FNDC5. It has been previously 249 documented that myonectin protein and mRNA levels are downregulated 250 after 12 weeks of high fat diet-induced obesity. Whereas, the data concerning 251 the relationship of FNDC5/Irisin with obesity and type 2 diabetes is varied 252 (14, 17-20, 31). Nevertheless, we found that the OZR had significantly higher 253 expression levels of both myonectin and FNDC5 compared with the LZR 254 (Figure 2A and 2B). There are a number of possibilities to explain this data. 255 The first is that leptin plays a role in the regulation of both FNDC5 and 256 myonectin. Obesity occurs in the OZR model due to a nonfunctioning leptin 257 receptor. Therefore, any leptin-mediated regulation which occurs in the high 258 fat diet-induced model of obesity would be absent in our model. This also 259 raises the possibility that leptin signaling may be a contributing factor in the 260 inconsistency regarding the relationship between BMI and FNDC5/irisin, as 261 leptin levels can vary significantly among person with a BMI less than 30 (32, 262 33). Previous analyses of the association between BMI and FNDC5/irisin were 263 across the entire spectrum of BMI $(14,17,18,28,30,31)$. Another possibility, 264 in regards to the discrepancy with myonectin data, is that a diet high in fat 265 may induce the expression myonectin regardless of obesity. Previous work 266 has demonstrated that mice challenged with a single dose of emulsified 267 intralipid will show an approximate $500 \%$ increase in circulating myonectin 
268 levels (12). In the OZR model of obesity, animals are fed a chow diet and 269 become obese due to excessive caloric intake (23-26). Nevertheless, this 270 finding may be serendipitous as these myokines have yet to be examined in 271 a model with dysfunctional leptin signaling. These observations deserve more 272 extensive analysis than was possible within the scope of the current study. A 273 third and unfortunate possibility is that the reference genes by which 274 previous studies normalized the gene expression were affected by the study 275 parameters and erroneously skewed the gene expression data.

276

277

278

279

280

281

282

283

284

285

286

287

Additionally, we attempted to measure irisin levels in the muscles samples using a commercially available antibody (Anti-FNDC5 antibody; ab131390). However, According to the manufactures there should be a band at $22 \mathrm{kDa}$ and an unidentified band at $\sim 45 \mathrm{kDa}$ (which corresponds to the size of FNDC5, but was unable to be confirmed within the constraints of this study). Although we successfully detected the band at $45 \mathrm{kDa}$, we only detected a faint band at $22 \mathrm{kDa}$ in some of the samples. Regardless there were no differences observed among the groups examined of either the $45 \mathrm{kDa}$ or 22 kDa band (data not shown). It is highly likely that differences may still be detected in circulating irisin levels, however as this study was a reexamination of previously acquired muscle samples the serum is no longer available from the animals studied.

288

289

The combined effects of Obesity and exercise training on Myonectin expression. It has been previously documented that short-term exercise 290 exposure (3-weeks free wheel running) increases the gene expression of 291

292

293

294

295

296

297

298

299

300

301 myonectin (12). Although myonectin expression had not been examined after long-term exercise exposure, we were surprised to find that chronic exercise (9-weeks) reduced myonectin expression regardless of obesity status (figure 2A). Because our findings were contrary to what we anticipated, we also examined the muscle protein content of myonectin (figure 3 ). These results were even more confounding, since, although myonectin gene expression was reduced with exercise, myonectin protein content was elevated with exercise, regardless of obesity. Unfortunately, serum samples were no longer available from these animals to determine the changes to circulating myonectin levels. However, these data suggest that myonectin may act in an autocrine fashion to regulated it's own expression, as has been reported 302 recently for irisin (34) and for other myokines such as IL-6 (35). This potential 303 autocrine regulation warrants further analysis, but was beyond the confines 304 of the current study.

305 The combined effects of Obesity and exercise training on FNDC5 gene 306 expression. According to the literature neither short-term nor chronic exercise 307 alters FNDC5 gene expression $(11,15)$. FNDC5 is the precursor for Irisin, and 308 it has been suggested that exercise causes cleavage of FNDC5, releasing 309 irisin and driving the exercise-induced 'browning' of white adipose tissue (11, 310 36). This indicates that FNDC5 levels may not be directly regulated by 311 exercise. However, because FNDC5 levels are reduced with obesity and 312 insulin resistance we expected to see a restoration of FNDC5 levels with 
313 exercise training in the insulin resistant obese OZR. Although we confirmed 314 that exercise did not effect FNDC5 gene expression, contrary to our initial 315 hypothesis we found that FNDC5 mRNA levels were elevated in the OZR 316 (figure 3B). As stated earlier, this finding indicates that FNDC5 may be 317 regulated by leptin, or by dietary fat content.

318 Conclusion. Both myonectin and irisin have been linked to improved 319 metabolic health outcomes. Myonectin coordinates lipid homeostasis in liver 320 and adipose tissue with the metabolic demands of skeletal muscles (12), 321 whereas, irisin increases energy expenditure in mice through the browning of 322 white adipose tissue (11). To date, the combined effects of exercise and 323 obesity on the regulation of myonectin and irisin have not been examined. 324 This study shows that in the OZR both myonectin and Fndc5 gene expression 325 are elevated. Further, contrary to previous findings, myonectin gene 326 expression was negatively regulated by exercise, regardless of obesity. The 327 findings of this study implicate leptin signaling and high fat diet as a potential 328 novel mechanism in the regulation of these proteins, and these possibilities 329 warrant future study. Unfortunately, serum samples were no longer available 330 to analyze the combined effect of exercise and obesity on the circulating 331 levels of these novel myokines. Future studies should consider examining the 332 circulating levels of these myokines in a leptin deficient model with and 333 without exercise or treatment with recombinant leptin.

334 Acknowledgements. We would like to thank the East Tennessee State University Molecular 335 biology Core Facility for support in completing quantitative Real-time PCR experiments. We 336 would like to thank the Lab of Stephen E Alway for providing the diaphragm muscles used in this 337 study. 
339 1. Ng M, Fleming T, Robinson M, Thomson B, Graetz N, Margono C, Mullany

340 EC, Biryukov S, Abbafati C, Abera SF, Abraham JP, Abu-Rmeileh NM, Achoki T,

341 AlBuhairan FS, Alemu ZA, Alfonso R, Ali MK, Ali R, Guzman NA, Ammar W,

342 Anwari P, Banerjee A, Barquera S, Basu S, Bennett DA, Bhutta Z, Blore J,

343 Cabral N, Nonato IC, Chang JC, Chowdhury R, Courville KJ, Criqui MH, Cundiff

344 DK, Dabhadkar KC, Dandona L, Davis A, Dayama A, Dharmaratne SD, Ding

345 EL, Durrani AM, Esteghamati A, Farzadfar F, Fay DF, Feigin VL, Flaxman A,

346 Forouzanfar MH, Goto A, Green MA, Gupta R, Hafezi-Nejad N, Hankey GJ,

347 Harewood HC, Havmoeller R, Hay S, Hernandez L, Husseini A, Idrisov BT,

348 Ikeda N, Islami F, Jahangir E, Jassal SK, Jee SH, Jeffreys M, Jonas JB,

349 Kabagambe EK, Khalifa SE, Kengne AP, Khader YS, Khang YH, Kim D, Kimokoti

350 RW, Kinge JM, Kokubo Y, Kosen S, Kwan G, Lai T, Leinsalu M, Li Y, Liang X, Liu

351 S, Logroscino G, Lotufo PA, Lu Y, Ma J, Mainoo NK, Mensah GA, Merriman TR,

352 Mokdad AH, Moschandreas J, Naghavi M, Naheed A, Nand D, Narayan KM,

353 Nelson EL, Neuhouser ML, Nisar MI, Ohkubo T, Oti SO, Pedroza A,

354 Prabhakaran D, Roy N, Sampson U, Seo H, Sepanlou SG, Shibuya K, Shiri R,

355 Shiue I, Singh GM, Singh JA, Skirbekk V, Stapelberg NJ, Sturua L, Sykes BL,

356 Tobias M, Tran BX, Trasande L, Toyoshima H, van de Vijver S, Vasankari TJ,

357 Veerman JL, Velasquez-Melendez G, Vlassov VV, Vollset SE, Vos T, Wang C,

358 Wang SX, Weiderpass E, Werdecker A, Wright JL, Yang YC, Yatsuya H, Yoon J,

359 Yoon SJ, Zhao Y, Zhou M, Zhu S, Lopez AD, Murray CJ, Gakidou E: Global,

360 regional, and national prevalence of overweight and obesity in children and

361 adults during 1980-2013: A systematic analysis for the global burden of

362 disease study 2013. Lancet. , 2014 
363 2. Bogardus C: Does insulin resistance primarily affect skeletal muscle?

364 Diabetes Metab Rev. 5:527-528, 1989

365 3. Norheim F, Raastad T, Thiede B, Rustan AC, Drevon CA, Haugen F:

366 Proteomic identification of secreted proteins from human skeletal muscle

367 cells and expression in response to strength training. Am J Physiol Endocrinol

368 Metab. 301:E1013-21, 2011

369 4. Henningsen J, Rigbolt KT, Blagoev B, Pedersen BK, Kratchmarova I:

370 Dynamics of the skeletal muscle secretome during myoblast differentiation.

371 Mol Cell Proteomics. 9:2482-2496, 2010

372 5. Northoff $H$, Berg A: Immunologic mediators as parameters of the reaction

373 to strenuous exercise. Int J Sports Med. 12 Suppl 1:S9-15, 1991

374 6. Haahr PM, Pedersen BK, Fomsgaard A, Tvede N, Diamant M, Klarlund K,

375 Halkjaer-Kristensen J, Bendtzen K: Effect of physical exercise on in vitro

376 production of interleukin 1, interleukin 6, tumour necrosis factor-alpha,

377 interleukin 2 and interferon-gamma. Int J Sports Med. 12:223-227, 1991

378 7. Ostrowski K, Rohde T, Asp S, Schjerling P, Pedersen BK: Chemokines are

379 elevated in plasma after strenuous exercise in humans. Eur J Appl Physiol.

$38084: 244-245,2001$

381 8. Stouthard JM, Romijn JA, Van der Poll T, Endert E, Klein S, Bakker PJ,

382 Veenhof $\mathrm{CH}$, Sauerwein HP: Endocrinologic and metabolic effects of

383 interleukin-6 in humans. Am J Physiol. 268:E813-9, 1995

384 9. Stouthard JM, Oude Elferink RP, Sauerwein HP: Interleukin-6 enhances

385 glucose transport in 3T3-L1 adipocytes. Biochem Biophys Res Commun.

386 220:241-245, 1996 
387 10. Sandler S, Bendtzen K, Eizirik DL, Welsh M: Interleukin-6 affects insulin

388 secretion and glucose metabolism of rat pancreatic islets in vitro.

389 Endocrinology. 126:1288-1294, 1990

390 11. Bostrom P, Wu J, Jedrychowski MP, Korde A, Ye L, Lo JC, Rasbach KA,

391 Bostrom EA, Choi JH, Long JZ, Kajimura S, Zingaretti MC, Vind BF, Tu H, Cinti

392 S, Hojlund K, Gygi SP, Spiegelman BM: A PGC1-alpha-dependent myokine that

393 drives brown-fat-like development of white fat and thermogenesis. Nature.

394 481:463-468, 2012

395 12. Seldin MM, Peterson JM, Byerly MS, Wei Z, Wong GW: Myonectin (CTRP15),

396 a novel myokine that links skeletal muscle to systemic lipid homeostasis. J

397 Biol Chem. 287:11968-11980, 2012

398 13. Polyzos SA, Kountouras J, Shields K, Mantzoros CS: Irisin: A renaissance in

399 metabolism? Metabolism. 62:1037-1044, 2013

400 14. Huh JY, Panagiotou G, Mougios V, Brinkoetter M, Vamvini MT, Schneider

401 BE, Mantzoros CS: FNDC5 and irisin in humans: I. predictors of circulating

402 concentrations in serum and plasma and II. mRNA expression and circulating

403 concentrations in response to weight loss and exercise. Metabolism. 61:1725-

404 1738, 2012

405 15. Brenmoehl J, Albrecht E, Komolka K, Schering L, Langhammer M, Hoeflich

406 A, Maak S: Irisin is elevated in skeletal muscle and serum of mice

407 immediately after acute exercise. Int J Biol Sci. 10:338-349, 2014

408 16. Kurdiova T, Balaz M, Vician M, Maderova D, Vlcek M, Valkovic L, Srbecky

409 M, Imrich R, Kyselovicova O, Belan V, Jelok I, Wolfrum C, Klimes I, Krssak M,

410 Zemkova E, Gasperikova D, Ukropec J, Ukropcova B: Effects of obesity, 
411 diabetes and exercise on Fndc5 gene expression and irisin release in human

412 skeletal muscle and adipose tissue: In vivo and in vitro studies. J Physiol.

413 592:1091-1107, 2014

414 17. Timmons JA, Baar K, Davidsen PK, Atherton PJ: Is irisin a human exercise

415 gene? Nature. 488:E9-10; discussion E10-1, 2012

416 18. Timmons JA, Larsson O, Jansson E, Fischer H, Gustafsson T, Greenhaff PL,

417 Ridden J, Rachman J, Peyrard-Janvid M, Wahlestedt C, Sundberg CJ: Human

418 muscle gene expression responses to endurance training provide a novel

419 perspective on duchenne muscular dystrophy. FASEB J. 19:750-760, 2005

420 19. Gallagher IJ, Scheele C, Keller P, Nielsen AR, Remenyi J, Fischer CP, Roder

421 K, Babraj J, Wahlestedt C, Hutvagner G, Pedersen BK, Timmons JA: Integration

422 of microRNA changes in vivo identifies novel molecular features of muscle

423 insulin resistance in type 2 diabetes. Genome Med. 2:9, 2010

424 20. Seo DY, Kwak HB, Lee SR, Cho YS, Song IS, Kim N, Bang HS, Rhee BD, Ko

425 KS, Park BJ, Han J: Effects of aged garlic extract and endurance exercise on

426 skeletal muscle FNDC-5 and circulating irisin in high-fat-diet rat models. Nutr

427 Res Pract. 8:177-182, 2014

428 21. Peterson JM, Bryner RW, Sindler A, Frisbee JC, Alway SE: Mitochondrial

429 apoptotic signaling is elevated in cardiac but not skeletal muscle in the obese

430 zucker rat and is reduced with aerobic exercise. J Appl Physiol. 105:1934-

4311943,2008

432 22. Peterson JM, Bryner RW, Frisbee JC, Alway SE: Effects of exercise and

433 obesity on UCP3 content in rat hindlimb muscles. Med Sci Sports Exerc.

$434 \quad 40: 1616-1622,2008$ 
435 23. Ogawa Y, Masuzaki H, Isse N, Okazaki T, Mori K, Shigemoto M, Satoh N,

436 Tamura N, Hosoda K, Yoshimasa Y: Molecular cloning of rat obese cDNA and

437 augmented gene expression in genetically obese zucker fatty (fa/fa) rats. J

438 Clin Invest. 96:1647-1652, 1995

439 24. Stern J, Johnson PR, Greenwood MR, Zucker LM, Hirsch J: Insulin resistance

440 and pancreatic insulin release in the genetically obese zucker rat. Proc Soc

441 Exp Biol Med. 139:66-69, 1972

442 25. Godbole V, York DA: Lipogenesis in situ in the genetically obese zucker

443 fatty rat (fa/fa): Role of hyperphagia and hyperinsulinaemia. Diabetologia.

$444 \quad 14: 191-197,1978$

445 26. Takaya K, Ogawa Y, Isse N, Okazaki T, Satoh N, Masuzaki H, Mori K,

446 Tamura N, Hosoda K, Nakao K: Molecular cloning of rat leptin receptor isoform

447 complementary DNAs--identification of a missense mutation in zucker fatty

$448(\mathrm{fa} / \mathrm{fa})$ rats. Biochem Biophys Res Commun. 225:75-83, 1996

449 27. Moore RL, Gollnick PD: Response of ventilatory muscles of the rat to

450 endurance training. Pflugers Arch. 392:268-271, 1982

451 28. Choi YK, Kim MK, Bae KH, Seo HA, Jeong JY, Lee WK, Kim JG, Lee IK, Park

452 KG: Serum irisin levels in new-onset type 2 diabetes. Diabetes Res Clin Pract.

453 100:96-101, 2013

454 29. Stengel A, Hofmann T, Goebel-Stengel M, Elbelt U, Kobelt P, Klapp BF:

455 Circulating levels of irisin in patients with anorexia nervosa and different

456 stages of obesity--correlation with body mass index. Peptides. 39:125-130,

$457 \quad 2013$ 
458 30. Moreno-Navarrete JM, Ortega F, Serrano M, Guerra E, Pardo G, Tinahones

459 F, Ricart W, Fernandez-Real JM: Irisin is expressed and produced by human

460 muscle and adipose tissue in association with obesity and insulin resistance. J

461 Clin Endocrinol Metab. 98:E769-78, 2013

462 31. Kurdiova T, Balaz M, Vician M, Maderova D, Vlcek M, Valkovic L, Srbecky

463 M, Imrich R, Kyselovicova O, Belan V, Jelok I, Wolfrum C, Klimes I, Krssak M,

464 Zemkova E, Gasperikova D, Ukropec J, Ukropcova B: Effects of obesity,

465 diabetes and exercise on Fndc5 gene expression and irisin release in human

466 skeletal muscle and adipose tissue: In vivo and in vitro studies. J Physiol.

467 592:1091-1107, 2014

468 32. Horn R, Geldszus R, Potter E, von zur Muhlen A, Brabant G:

469 Radioimmunoassay for the detection of leptin in human serum. Exp Clin

470 Endocrinol Diabetes. 104:454-458, 1996

471 33. Scholz GH, Englaro P, Thiele I, Scholz M, Klusmann T, Kellner K, Rascher

472 W, Blum WF: Dissociation of serum leptin concentration and body fat content

473 during long term dietary intervention in obese individuals. Horm Metab Res.

$474 \quad 28: 718-723,1996$

475 34. Vaughan RA, Gannon NP, Barberena MA, Garcia-Smith R, Bisoffi M,

476 Mermier CM, Conn CA, Trujillo KA: Characterization of the metabolic effects of

477 irisin on skeletal muscle in vitro. Diabetes Obes Metab. , 2014

478 35. Bustamante M, Fernandez-Verdejo R, Jaimovich E, Buvinic S: Electrical

479 stimulation induces IL-6 in skeletal muscle through extracellular ATP by

480 activating $\mathrm{ca}(2+)$ signals and an IL-6 autocrine loop. Am J Physiol Endocrinol

481 Metab. 306:E869-82, 2014 
482 36. Castillo-Quan JI: From white to brown fat through the PGC-1alpha-

483 dependent myokine irisin: Implications for diabetes and obesity. Dis Model

484 Mech. 5:293-295, 2012

485 


\title{
Table 1 (on next page) \\ Baseline characteristics of study animals
}

\begin{abstract}
Values are means + SE; $n$, no. of animals. LZR, lean Zucker rat; EX, exercise; SED, nonexercised; OZR, obese Zucker rat. ${ }^{*} P+0.05$ vs. Sed.
\end{abstract}




\begin{tabular}{lllll}
\hline & $\begin{array}{l}\text { LZR-SED } \\
(\mathrm{n}=8)\end{array}$ & $\begin{array}{l}\text { LZR-EX } \\
(\mathrm{n}=8)\end{array}$ & $\begin{array}{l}\text { OZR- } \\
\text { SED } \\
(\mathrm{n}=8)\end{array}$ & $\begin{array}{l}\text { OZR-EX } \\
(\mathrm{n}=8)\end{array}$ \\
\hline Mass, g & $358 \pm 18$ & $360 \pm 1$ & $685 \pm 24$. & $502 \pm 2$ \\
& & 9 & 5 & $4^{*}$ \\
Blood glucose, & $116 \pm 9$ & $108 \pm 1$ & $188 \pm 24$ & $179 \pm 4$ \\
$\mathrm{mg} / \mathrm{dl}$ & & 0 & & $1^{*}$ \\
Plasma insulin, & $1.5 \pm 0.4$ & $1.3 \pm 0$. & $10.7 \pm 1$. & $6.7 \pm 1$. \\
$\mathrm{ng} / \mathrm{ml}$ & & 5 & 2 & 6 \\
\hline
\end{tabular}




\title{
Table 2 (on next page) \\ Rat Housekeeping Genes
}

\begin{abstract}
Variability of reference genes was deemed to be unacceptable if the maximum difference among the four groups was greater than $0.5 \mathrm{Cq}$. Reference genes examined are listed in table 1. Cq, quantification cycle.
\end{abstract}




\begin{tabular}{lcc} 
Gene Name & $\begin{array}{l}\text { Abbreviatio } \\
\mathbf{n}\end{array}$ & $\begin{array}{c}\text { Maximum Cq } \\
\text { Difference }\end{array}$ \\
\hline Actin, beta & Actb & 1.4 \\
Beta-2 microglobulin & B2m & 1.0 \\
Hypoxanthine & Hprt1 & .5 \\
phosphoribosyltransferase 1 & Hsp90 & .49 \\
Heat shock protein 90 alpha & Ldha & .19 \\
Lactate dehydrogenase A & Nono & .78 \\
Non-POU domain containing & Pgk1 & .36 \\
Phosphoglycerate kinase 1 & Ppih & .61 \\
Peptidylprolyl isomerase H & Rplp1 & .44 \\
RPLP1 ribosomal protein, large, P1 & Sdha & .33 \\
Succinate dehydrogenase complex, & Tbp & .85 \\
subunit A & Tfrc & 1.13 \\
TATA box binding protein & & \\
Transferrin receptor &
\end{tabular}




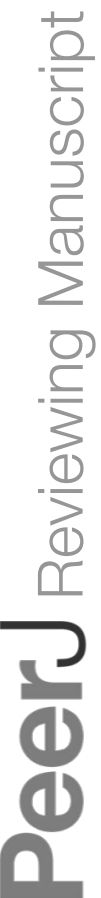

PeerJ reviewing PDF | (v2014:06:2220:1:2:NEW 2 Sep 2014) 


\title{
Table 3(on next page) \\ Quantitative real time PCR analysis
}

\begin{abstract}
Validated PCR primers for Myonectin, FNDC5/irisin, Hprt1, Ldha, and RN18S were purchased from SABiosciences.
\end{abstract}




\begin{tabular}{|c|c|c|c|}
\hline Gene Name & $\begin{array}{c}\text { Abbreviatio } \\
\text { n }\end{array}$ & Accession \# & $\begin{array}{l}\text { Catalog } \\
\text { number }\end{array}$ \\
\hline $\begin{array}{l}\text { Hypoxanthine } \\
\text { phosphoribosyltransfer } \\
\text { ase } 1\end{array}$ & Hprt1 & NM_012583.2 & PPR42247F \\
\hline 18S ribosomal RNA & RN18S & NR_046237.1 & PPR72042A \\
\hline $\begin{array}{l}\text { Lactate dehydrogenase } \\
\text { A }\end{array}$ & Ldha & NM_017025 & PPR56603 \\
\hline $\begin{array}{l}\text { Myonectin; C1q TNF } \\
\text { Related Protein 15; } \\
\text { Family with sequence } \\
\text { similarity 132, member } \\
\text { B }\end{array}$ & Myonectin & $\begin{array}{l}\text { XM_001060107. } \\
2\end{array}$ & PPR68386A \\
\hline $\begin{array}{l}\text { Fibronectin type III } \\
\text { domain-containing } \\
\text { protein 5; also known } \\
\text { as irisin }\end{array}$ & Irisin & $\begin{array}{l}\text { XM_001060505. } \\
2\end{array}$ & PPR46702A \\
\hline
\end{tabular}




\section{Figure 1}

Reference Genes and Mitochondria Protien

A) To screen reference genes for relative stability pooled cDNA for each group was examined to determine the Cq number by PCR array ( $\mathrm{RT}^{2}$ Profiler PCR Array; Rat Housekeeping Genes; Qiagen PARN-000ZA). B) Mitochondrial protein COX IV was measured in the Lean and obese animals as a marker of total mitochondrial content. Representative blots are show. The data are expressed in arbitrary units with values normalized to mean control value within phenotype. Abbreviations: Cq, quantification cycle; LZR, Lean Zucker Rat; OZR, Obese Zucker Rat; ET, Exercise trained; Actb, Actin, beta; B2m, Beta-2 microglobulin; Hprt1, Hypoxanthine phosphoribosyltransferase 1; Hsp90, Heat shock protein 90 alpha (cytosolic), class B member 1; Ldha, Lactate dehydrogenase A; Nono, Non-POU domain containing, octamer-binding; Pgk1, Phosphoglycerate kinase 1; Ppih, Peptidylprolyl isomerase $\mathrm{H}$ (cyclophilin H); Rplp1, Ribosomal protein, large, P1; Sdha, Succinate dehydrogenase complex, subunit A, flavoprotein (Fp); Tbp, TATA box binding protein; Tfrc, Transferrin receptor; COX IV, Cytochrome c Oxidase Subunit IV. 
Reference Gene Array
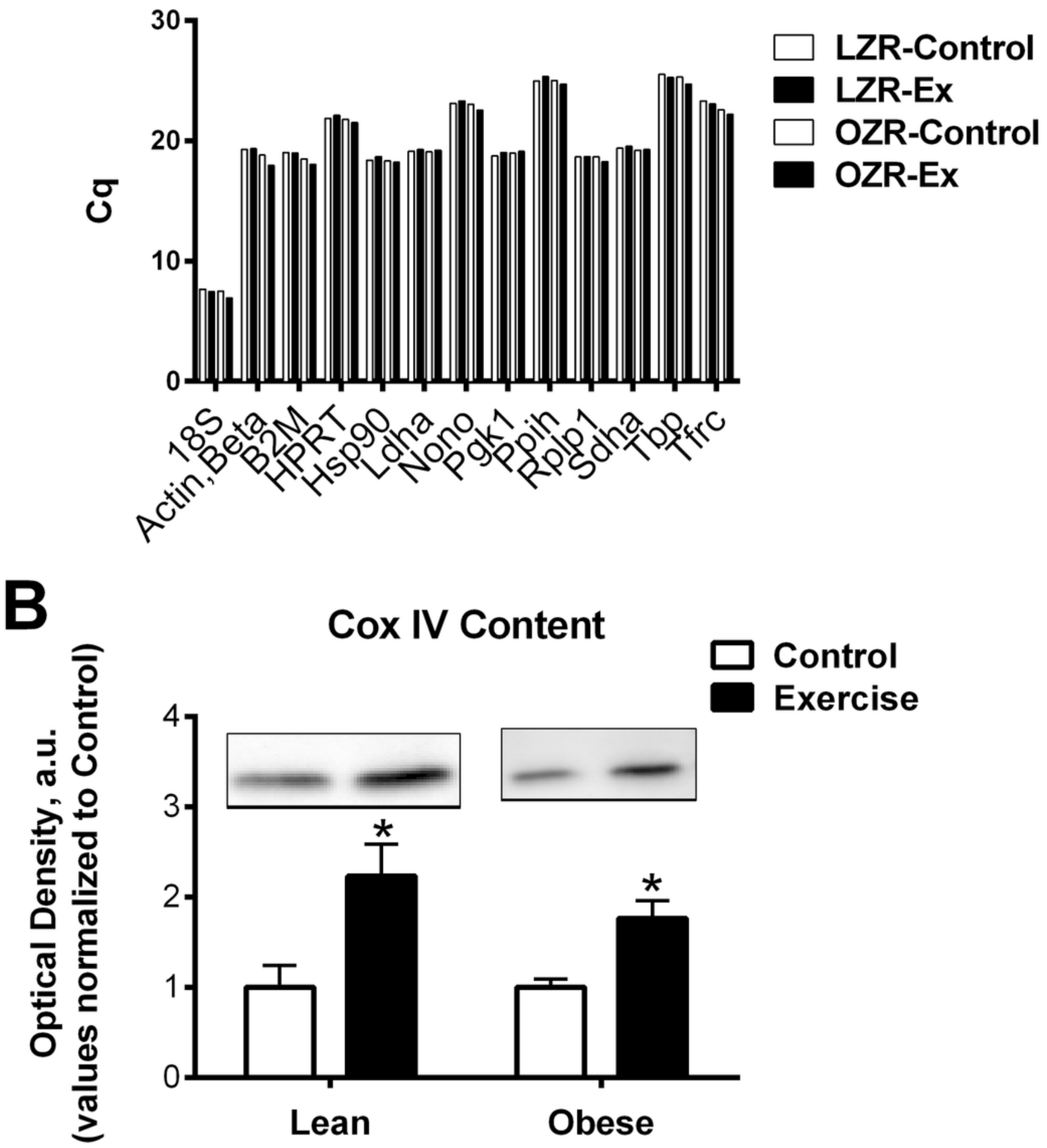


\section{Figure 2}

Quantitative RNA analysis

Myonectin (A), FNDC5/irisin (B), RN18S (C), Ldha (D), and Hprt1 (E). Validated PCR primers were purchase from SABiosciences (Table 3). A standard curve was generated from 10-fold dilution series of DNA amplicons for each gene of interest. All qRT-PCR primers displayed a coefficient of correlation greater than 0.99 and efficiencies between $90 \%$ and $110 \%$. Data is reported as copy number per amount of starting RNA. The main effects of obesity (OZR $x$ LZR) and exercise interaction (obesity $x$ exercise) in these animals were analyzed by a twoway ANOVA. Data are presented as means \pm SE. ${ }^{*} p<0.05$, data significantly different between control and exercised groups. ${ }^{* *} \mathrm{p}<0.05$, data from OZR animals was significant different from the LZR animals. 
A

FAM132b (myonectin)

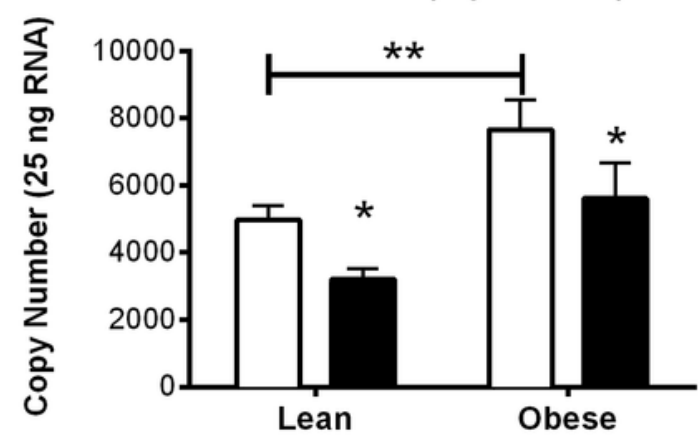

C

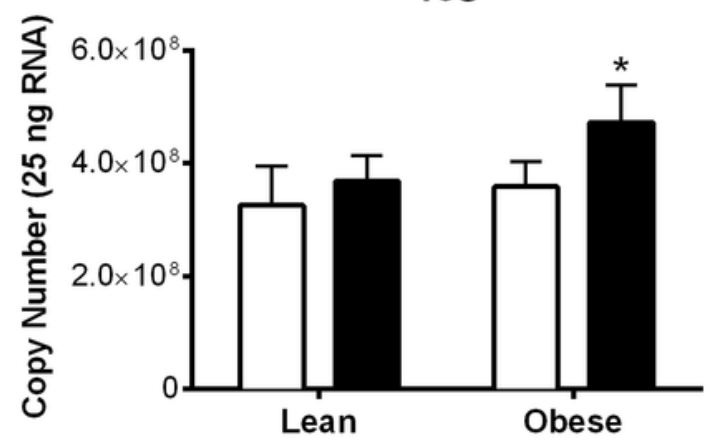

E

Hypoxanthine Phosphoribosyltransferase 1

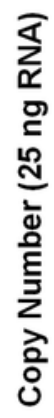

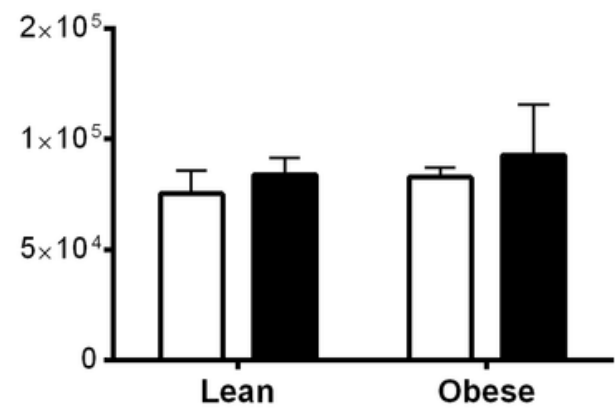

B

FNDc5 (Irisin)

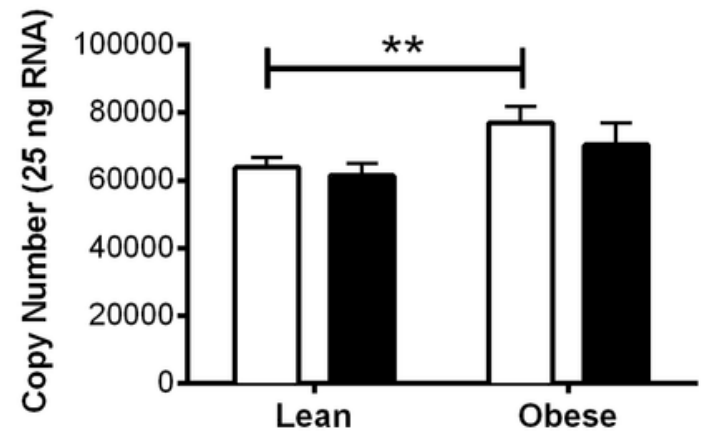

D

Lactate dehydrogenase A

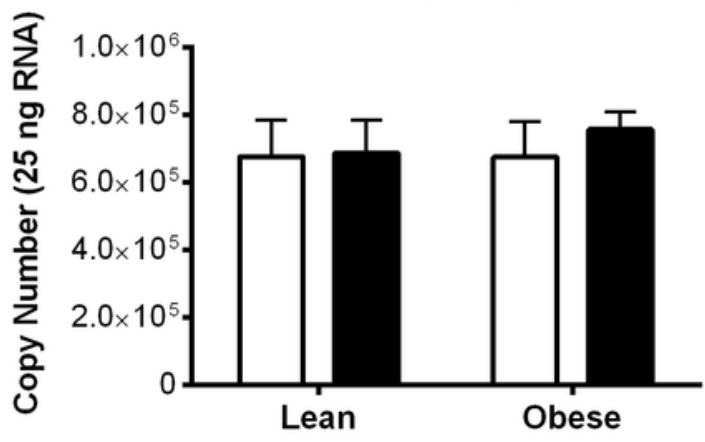

$\square$ Control

Exercised 


\section{Figure 3}

Relative Myonectin/CTRP15 content

Relative Myonectin/CTRP15 content was examined in the rat diaphragm muscle of the male lean zucker (LZR) and obese zucker rats (OZR). Exercised animals were trained on a motorized treadmill for 9 wk. Control (animals were exposed to the similar environment (positioned next to the treadmill) but were not exercised. A) Shows representative western blots for Myonectin and GAPDH. B) The data are expressed in arbitrary units with values normalized to mean control value within phenotype. span $>$ aw 8 
A
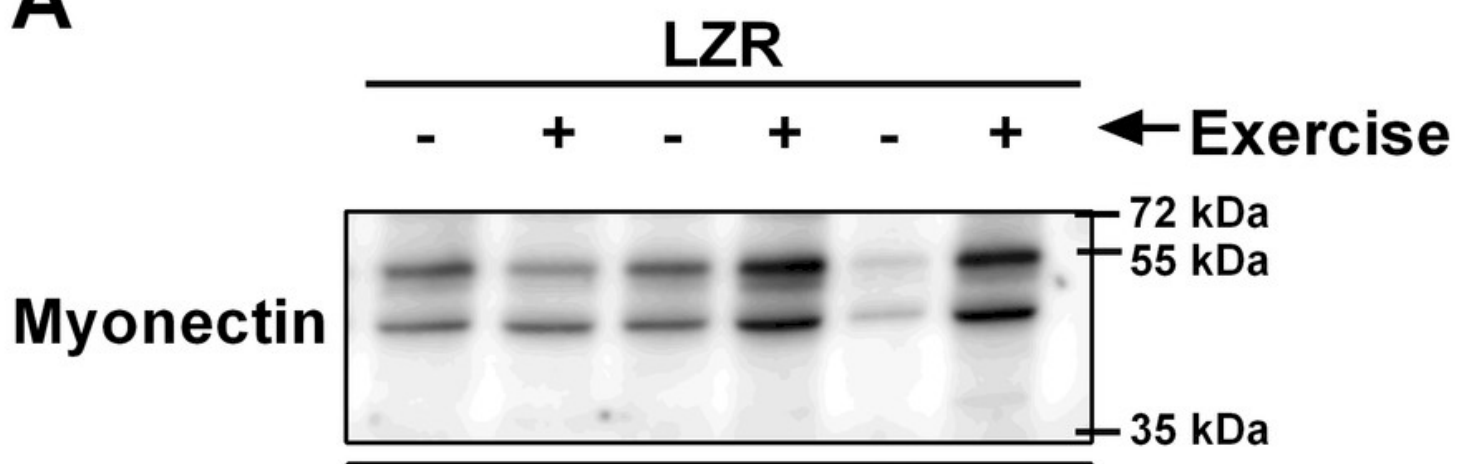

GAPDH
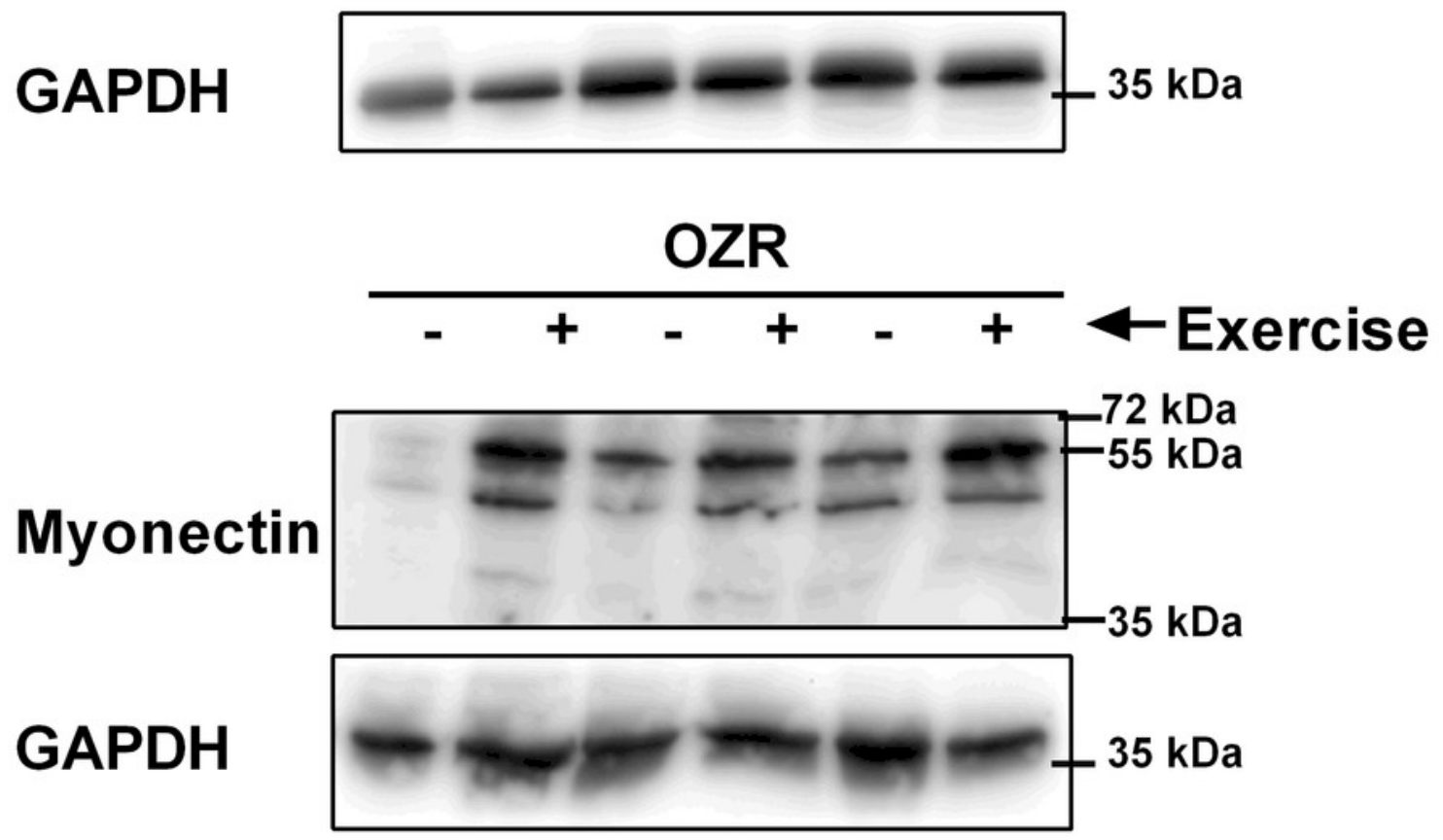

B

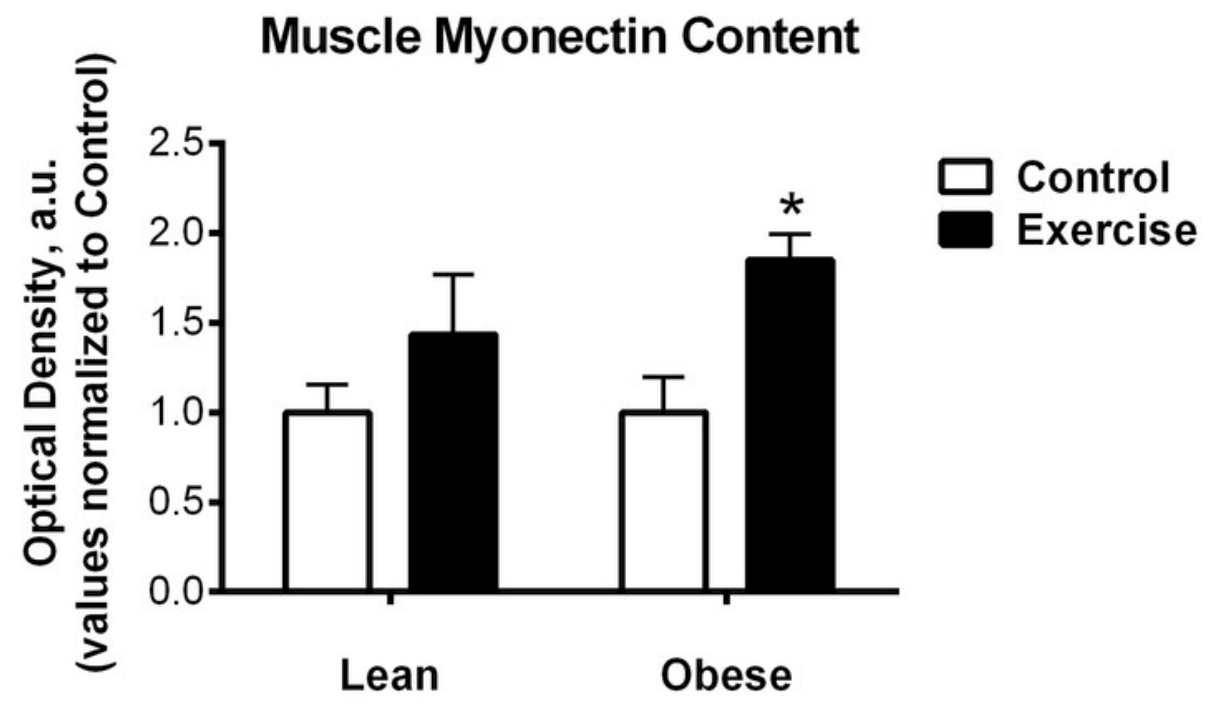

